\title{
Handling of Incidents in the Clinical Application of Ionizing Radiation in Diagnostic and Interventional Radiology - a Multi-center Study
}

\author{
Umgang mit unbeabsichtigten Expositionen bei medizinischen \\ Anwendungen ionisierender Strahlung in der Röntgendiagnostik \\ und interventionellen Radiologie - eine Multi-Center-Studie
}

Authors

Birgit Sabine Müller ${ }^{1}$, Julian Singer ${ }^{1}$, Georg Stamm², Lukas Pirl ${ }^{3}$, Markus Borowski ${ }^{3}$, Thomas Hertlein ${ }^{1}$, Eugenia Rerich ${ }^{1,4}$, Sebastian Trinkl' ${ }^{5}$, Michael Wucherer ${ }^{1}$, Josefin Ammon ${ }^{1}$

Affiliations

1 Institute of Medical Physics, Klinikum Nurnberg, Paracelsus Medical University, Nurnberg, Germany

2 Institute for Diagnostic and Interventional Radiology, University Medical Center Gottingen, Gottingen, Germany

3 Institute for Diagnostic Radiology and Nuclear medicine, Braunschweig Municipal Hospital, Braunschweig, Germany

4 Medizinphysik-Experten für sonstige Einrichtungen, Charite University Hospital Berlin, Germany

5 External and Internal Dosimetry, Biokinetics, Federal Office for Radiation Protection Neuherberg, Germany

Key words

diagnostic radiology, QA/QC, radiation safety, CIRS, incidents, notification criteria

received 28.03.2021

accepted 30.09.2021

published online 21.12.2021

Bibliography

Fortschr Röntgenstr 2022; 194: 400-408

DOI 10.1055/a-1665-6988

ISSN 1438-9029

(c) 2021. Thieme. All rights reserved.

Georg Thieme Verlag KG, Rüdigerstraße 14,

70469 Stuttgart, Germany

Correspondence

Dr. Josefin Ammon

Institute of Medical Physics, Klinikum Nurnberg Nord,

Prof.-Ernst-Nathan-Str. 1, 90419 Nurnberg, Germany

Tel.: +49/911/398114781

josefin.ammon@klinikum-nuernberg.de

\section{ABSTRACT}

Purpose According to the German legislation and regulation of radiation protection, i. e. Strahlenschutzgesetz und Strahlenschutzverordnung (StrISchG and StrlSchV), which came into force on $31^{\text {st }}$ December 2018, significant unintended or accidential exposures have to be reported to the competent authority. Furthermore, facilities have to implement measures to prevent and to recognize unintended or accidental exposures as well as to reduce their consequences. We developed a process to register incidents and tested its application in the framework of a multi-center-study.

Materials and Methods Over a period of 12 months, 16 institutions for $x$-ray diagnostics and interventions, documented their incidents. Documentation of the incidents was conducted using the software CIRSrad, which was developed, released for testing purposes and implemented in the frame of the study. Reporting criteria of the project were selected to be more sensitive compared to the legal criteria specifying "significant incidents". Reported incidents were evaluated after four, eight, and twelve months. Finally, all participating institutions were interviewed on their experience with the software and the correlated effort.

Results The rate of reported incidents varied between institutions as well as between modalities. The majority of incidents were reported in conventional $x$-ray imaging, followed by computed tomography and therapeutic interventions. Incidents were attributed to several different causes, amongst others to the technical setup and patient positioning (19\%) and patient movement or insufficient cooperativeness of the patient (18\%). Most incidents were below corresponding thresholds stated in StrlSchV. The workload for documenting the incidents was rated as appropriate.

Conclusion It is possible to monitor and handle incidents complient with legal requirements with an acceptable effort. The number of reported incidents can be increased by frequent trainings on the detection and the processing workflow, on the software and legal regulation as well as by a transparent error handling within the institution.

Key Points:

- The software CIRSrad was developed to enable the present study and as prototype platform for a future radiological incident management system.

- 586 exceedances of thresholds were recorded by 16 facilities in a period of one year.

- Frequent trainings of all users increase the number of reported cases. 


\section{Citation Format}

- Müller BS, Singer J, Stamm G et al. Handling of Incidents in the Clinical Application of Ionizing Radiation in Diagnostic and Interventional Radiology - a Multi-center Study.

Fortschr Röntgenstr 2022; 194: 400-408

\section{ZUSAMMENFASSUNG}

Ziel Entsprechend dem zum 31. Dezember 2018 in Kraft getretenen Strahlenschutzgesetz und der -verordnung (StrISchG und StrISchV) sind bedeutsame Vorkommnisse bei der Anwendung ionisierender Strahlung der zuständigen Behörde zu melden. Zudem sind Maßnahmen zu treffen, um Vorkommnisse zu vermeiden, zu erkennen und deren Auswirkungen so gering wie möglich zu halten. Im Rahmen einer MultiCenter-Studie wurde ein Verfahren zur Erfassung von Vorkommnissen entwickelt und dessen Anwendung getestet.

Material und Methoden Über einen Erfassungszeitraum von 12 Monaten dokumentierten 16 verschiedene röntgendiagnostische Einrichtungen Interventionsschwellenüberschreitungen (IntS-Überschreitungen). Zur Dokumentation der IntS-Überschreitungen wurde die Software CIRSrad entwickelt und in den teilnehmenden Einrichtungen implementiert. Die Kriterien zur Definition einer IntS-Überschreitung lagen größtenteils unterhalb der Definition eines Vorkommnisses nach der StrISchV und wurden weiter gefasst. Alle gemelde- ten IntS-Überschreitungen wurden nach 4, 8 und 12 Monaten ausgewertet. Abschließend wurden die Studienteilnehmer zur Nutzung der Software und dem damit verbundenen Aufwand befragt.

Ergebnisse Die Meldequote variierte zwischen den Einrichtungen sowie zwischen den Modalitäten. Aus dem Bereich der Projektionsradiografie wurden die meisten IntS-Überschreitungen gemeldet, gefolgt von der Computertomografie und der therapeutischen Intervention. IntS-Überschreitungen waren auf zahlreiche unterschiedliche Ursachen zurückzuführen, darunter auf die Einstelltechnik (19\%) sowie Bewegung oder mangelnde Kooperationsbereitschaft der Patienten (18\%). Die IntS-Überschreitungen lagen größtenteils unterhalb der gesetzlichen Meldeschwellen eines Vorkommnisses. Der Aufwand für die Erfassung wurde als angemessen bewertet.

Schlussfolgerung Eine wenig aufwendige, den Anforderungen des Strahlenschutzrechts genügende und im Sinne des Risikomanagements sinnvolle Erfassung von Vorkommnissen ist möglich. Regelmäßige Schulungen zur Erkennung von Vorkommnissen und deren Abhandlung, im Umgang mit der Software und bzgl. der rechtlichen Situation aller Beteiligten, sowie ein offener Umgang mit Fehlern im Betrieb erhöhen die Anzahl an Meldungen.

\section{Introduction}

The German Radiation Protection Act of June 27, 2017 which implements the European Directive 2013/59/Euratom in national law, and the new Radiation Protection Ordinance of November 29, 2018, bring "significant incidents" in the use of ionizing radiation in medicine into focus [1]. Paragraf 90 of the act requires both the initiation of measures for the detection, elimination and prevention of reportable incidents as well as the reporting of significant incidents to the supervisory authority. The Radiation Protection Ordinance specifies the duties of those responsible for radiation protection, the tasks and powers of the authorities, and the definition of reportable incidents. According to paragraph 108 of the ordinance, a significant occurrence must be reported to the competent authority, especially if it meets criteria of Annex 14 and 15 .

The basic prerequisite for this is the recognition of an incident. This requires constant monitoring of medical-related radiation exposures and addressing any unintended exposures. This is followed by complete documentation and evaluation of the incident with the decision whether there is a reporting obligation according to paragraph 108 of the ordinance. Independent of a report, a systematic investigation as well as the initiation of appropriate countermeasures are necessary to avoid similar incidents in the future.

Critical Incident Reporting Systems (CIRS) are used to record unintentional exposures and near-exposures. So far, CIRS are mainly known in the field of general clinical processes and radia- tion therapy [2-9]. Very little has been published on this topic in the area of diagnostic radiology. Possible categorizations of incidents as well as draft criteria based on consequential damages, among others, are available [10, 11, 13-15]. In this regard, all relevant publications are of the opinion that a radiological CIRS is a useful and valuable quality management tool that can be used to detect gaps in safety measures and initiate necessary changes in process procedures.

Sendlhofer et al. have summarized requirements for a functioning CIRS [16]. For users, sufficient information about the CIRS, the guarantee of anonymity, confidentiality with accompanying freedom from sanctions ("safety culture" instead of "culture of blame") and a transparent feedback mechanism play an essential role. Current CIRS for general errors in the daily routine of a practice or hospital are mostly web-based, anonymous systems that allow users to make their own comments and provide feedback in the form of regular reports [17-19]. However, these products and the underlying workflows are of limited use for the special issues and legal requirements in X-ray diagnostics. They also usually do not contain a process step for evaluation by radiation protection officers (or responsible persons) and for reporting to the authorities.

The CIRSrad [22] software was developed for incidents in radiology and nuclear medicine and tested as part of a multicenter study in the course of the departmental research projects initiated by the German Federal Office for Radiation Protection (BfS) "Operational handling of (significant) incidents in medical applications of ionizing radiation in $\mathrm{X}$-ray diagnostics and intervention- 
- Table 1 Reporting criteria for intervention threshold violations for all institutions, with differences in the respective criteria for increased dose with MG: Mammography, TI: Therapeutic Intervention, DI: Diagnostic Intervention, PR: Projection Radiography, DVT: Digital Volume Tomography, CT: Computed Tomography, DTDI: Computed Tomography Dose Index, DAP: Dose Area Product, DRV Diagnostic Reference Value.

\begin{tabular}{|c|c|c|c|c|c|}
\hline & СT & DI & TI & DVT & PR/MG \\
\hline Excess dose (adult) & $\begin{array}{l}\mathrm{CTDI}_{\text {head }}>100 \mathrm{mGy}, \\
\mathrm{CTDI}_{\text {body }}>50 \mathrm{mGy}\end{array}$ & DAP > 15000 cGycm² & $\mathrm{DAP}>50000 \mathrm{cGycm}{ }^{2}$ & $\begin{array}{l}\text { DAP } \gg \text { in-house } \\
\text { reference value }\end{array}$ & \\
\hline excess dose (child) & CTDI > doubled DRV & DAP $>$ doubled DRV & DAP $>$ doubled DRV & - & - \\
\hline repeat examination & $\mathrm{x}$ & $\mathrm{x}$ & $\mathrm{x}$ & $\mathrm{x}$ & $\mathrm{x}$ \\
\hline wrong patient & $\mathrm{x}$ & $\mathrm{x}$ & $\mathrm{x}$ & $\mathrm{x}$ & $\mathrm{x}$ \\
\hline $\begin{array}{l}\text { incorrect examination/ } \\
\text { incorrect performance }\end{array}$ & $\mathrm{x}$ & $\mathrm{x}$ & $\mathrm{x}$ & $\mathrm{x}$ & $\mathrm{x}$ \\
\hline device error/failure & $\mathrm{x}$ & $\mathrm{x}$ & $\mathrm{x}$ & $\mathrm{x}$ & $\mathrm{x}$ \\
\hline deterministic skin damage & $\mathrm{x}$ & $\mathrm{x}$ & $\mathrm{x}$ & $\mathrm{x}$ & $\mathrm{x}$ \\
\hline unintended prenatal exposure & $\mathrm{x}$ & $\mathrm{x}$ & $\mathrm{x}$ & $\mathrm{x}$ & $\mathrm{x}$ \\
\hline dose $>1 \mathrm{mSv}$ to support staff & $\mathrm{x}$ & $\mathrm{x}$ & $\mathrm{x}$ & $\mathrm{x}$ & $\mathrm{x}$ \\
\hline contrast medium extravasation & $\mathrm{x}$ & $\mathrm{x}$ & $\mathrm{x}$ & $\mathrm{x}$ & $\mathrm{x}$ \\
\hline
\end{tabular}

al radiology and practical testing of the reporting criteria” [20] and "Operational handling of (significant) incidents in medical applications of radioactive substances in nuclear medicine and practical testing of the reporting criteria" [21]. Intervention thresholds were defined for the clinical trial, most of which were below the legal criteria of reportable incidents according to the Radiation Protection Ordinance in force since December 31, 2018. In this paper, the term "incidents" describes violations of the intervention thresholds developed here, rather than the legally-defined "significant incidents".

The aim of this study was the realization of software for recording and processing of incidents and its application in order to obtain initial experiences with incident types as well as the scope of recording in clinical practice.

\section{Materials and Methods}

\section{Study participants and reporting criteria}

Sixteen institutions of varying sizes, including five university hospitals, five non-academic hospitals and six practices (three radiology, one cardiology, two dental), were recruited for project participation. The facilities differed in their technical equipment. Thus, a radiology practice with only computed tomography (CT) scanners participated, as well as clinics possessing multiple systems offering all modalities. The number of examinations and therapies performed per modality ranged from 0 to 55000 per year for computed tomography scans, from 0 to 130000 for projection radiography and mammography, and from 0 to 5500 for interventions, depending on the institution. For evaluation purposes, facility sizes were divided into the following categories: University hospitals and large clinics (A), small hospitals and large practices (B), and individual, stand-alone practices (C).
The lower-threshold reporting criteria defined for the project, the intervention thresholds, included more incidents than the legally prescribed criteria of a reportable incident according to the Radiation Protection Ordinance (see $>$ Table 1). Every repeated exposure as well as confusion of body parts and patients was reportable, regardless of the applied dose. Likewise, projection radiographs and mammograms were included in the criteria.

Facilities recorded incidents exceeding the intervention threshold over a one-year period in 2018 and 2019.

\section{Recording intervention threshold violations}

The CIRSrad software developed to record incidents exceeding the intervention threshold [22] replicates the entire process of facility-wide standardized recording, including assessment and documentation of a significant incident relevant to this project.

The user interface of CIRSrad enables the direct entry of an incident or violation of an intervention threshold via drop-down lists for the modality and, based on this, possible types of incidents, such as wrong patient, excess dose, etc. (see - Fig. 1). In addition to recording radiation protection-relevant incidents, a separate tab can also be used to document "other incidents" that are not significant in terms of radiation protection, but are important for reasons of general quality management. The administrative component of the software contains the corresponding work steps to evaluate and, if necessary, to report a significant incident to the responsible authority. The average initial input time is about two minutes (specifying the modality, incident type and access number), the time required for the subsequent steps depends primarily on the type of incident. The initial mandatory fields (highlighted in orange in $\mathbf{F i g . 1}$ ) could be customized by the respective institutions. The setup of the software was, with uncomplicated configuration, one hour per separately entered setup. 


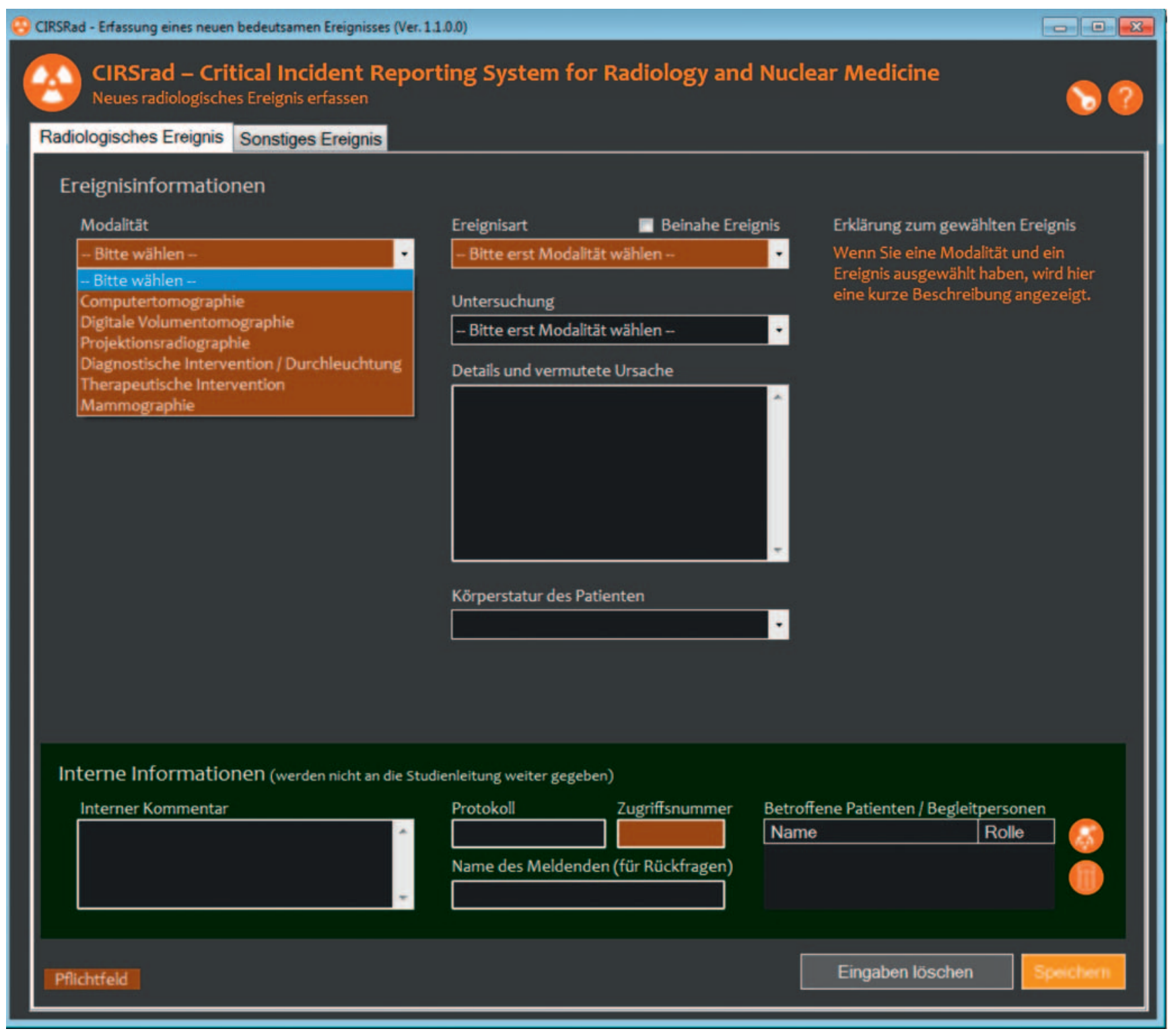

- Fig. 1 German user interface for entering an incident or intervention threshold violation in CIRSrad [22]. First, the intervention threshold violation in this project is distinguished by modality and then by incident type.

\section{Evaluation}

After recording periods of four, eight and twelve months, the data collected from the study participants were analyzed by the study management. Intervention threshold violations were assessed according to institution, modality, incident type and cause. Finally, an anonymous online questionnaire was conducted among all participating institutions, which particularly surveyed the effort and ergonomics of processing reports with CIRSrad.

\section{Results}

The one-year recording period in 2018 and 2019 identified 586 intervention threshold violations, including 581 meeting the criteria of this research project, and five near-violations. Near-intervention threshold violations describe almost-occurring violations that were discovered outside of the quality assurance measures. In the first period 269, in the second period 183 and in the third period 134 intervention threshold violations were registered. The facilities differed in the number of reported incidents (see - Fig. 2). Few institutions reported continuously during all time periods. Three institutions of different sizes recorded no incidents over the entire period of the survey.

Most violations (272 reports) were recorded in the area of projection radiography, followed by computed tomography (CT) (147) and therapeutic intervention (104). Broken down by incident type, repeat projection radiographs (224) formed the largest group of reported threshold exceedances (see $>$ Fig. 3), followed by excess dose exposures during therapeutic interventions (99) and repeated CT examinations (59). No excess doses related to radiation exposure of support staff were reported. 


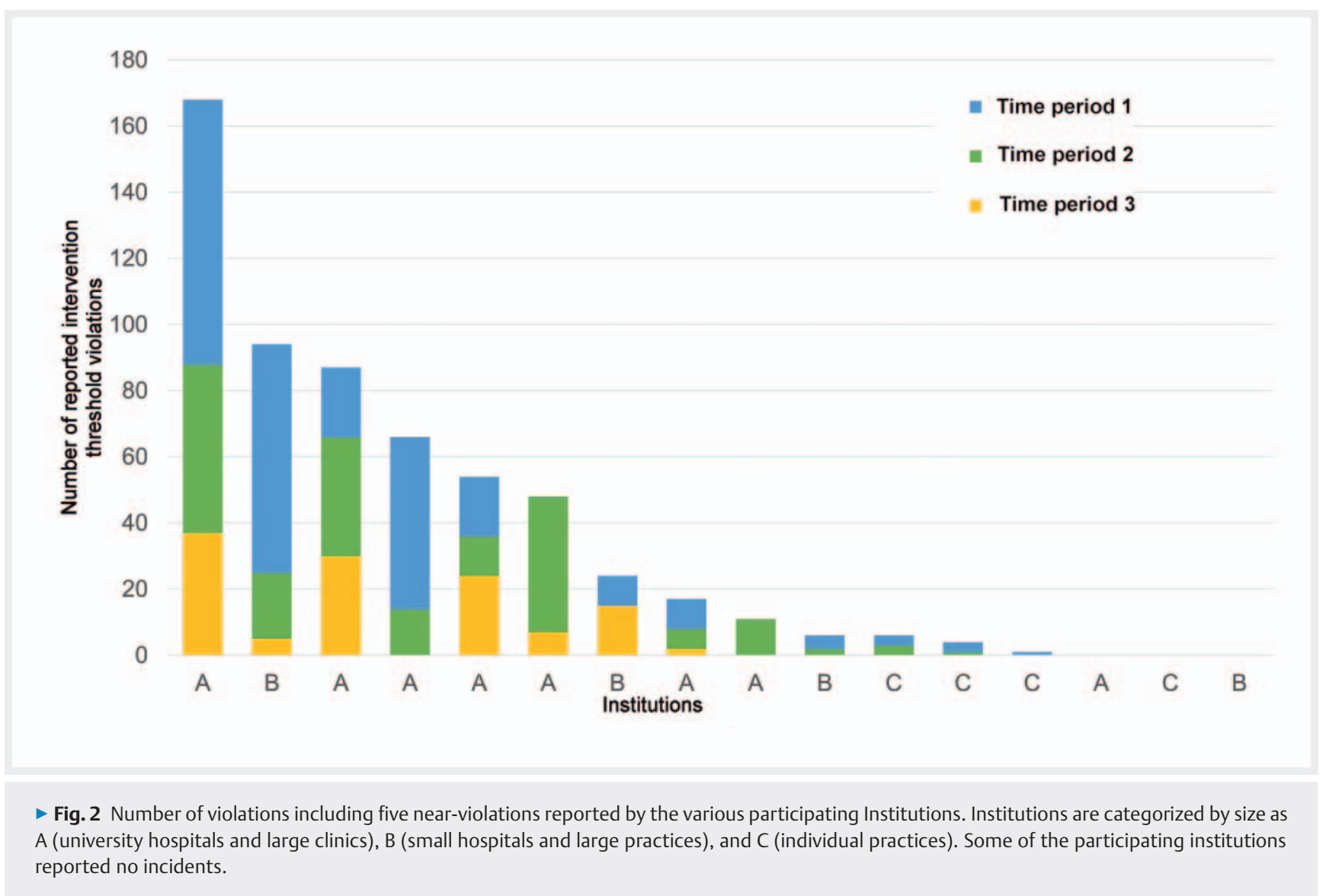

Of the reported threshold violations, $19 \%$ were due to setup technique, $18 \%$ were caused by patient movement or lack of cooperation, and $14 \%$ resulted from a complex treatment modality. No cause was mentioned in $20 \%$ of reports.

In the voluntary, anonymous online survey, the effort required to record threshold breaches using CIRSrad was rated as appropriate. Of each participant group, $33 \%$ estimated the proportion of threshold violations recorded to be between $76 \%$ and $100 \%$ and between $51 \%$ and $75 \%$, respectively (see $>$ Fig. 4 ). A recording rate of 0 to $25 \%$ and $26 \%$ to $50 \%$ was assumed by $17 \%$ of the survey participants. The reasons given for the failure to record exceedances included "concerns about the consequences" and "lack of time" or "additional workload".

A guideline [23] was developed as part of the research project for the systematic treatment of threshold violations [20, 21] which is available as a free download for interested parties. This can be consulted to plan the facility-specific process starting with detection, through recording and documentation, to assessment and further handling of incidents. The guideline covers processes for institutions of different sizes and for orientation, lists possible systems to be used as well as the groups of personnel involved.

\section{Discussion}

In the course of the research project 586 incidents were registered. The institutions differed significantly in the number of reported incidents. The size of the institutions with respect to equipment and number of examinations performed per year, as well as the number of admissions per modality, varied greatly among the institutions. No correlation could be established between facility size and the number of reported threshold violations. Likewise, no correlation between institution size and number of violations could be established.

Given the study experience and the one year recording period, it is unlikely that there were no occurrences of threshold violations, especially at larger institutions. For example, an eightweek recording study of faulty images in projection radiography showed that, averaged over all examination regions, approx. $7 \%$ of the acquired images were faulty [24]. Similarly, it can be assumed that the actual number of threshold violations exceeds the number of recorded incidents, which is also indicated by the data of the estimated proportion of recorded violations in the online survey. The number of reports, which varies and is not correlated with the size of the institution, illustrates the importance of the reporting person. Whether an accidental exposure or near exposure is acquired in the system is primarily personnel-dependent.

Overall, reports decreased over the period of record. A clear decrease was particularly evident in the repeat exposures of the $\mathrm{X}$-ray projection images. Here, a correlation with the entry into force of the Radiation Protection Ordinance during the second recording period is conceivable. In contrast to the study criteria, projection images are explicitly excluded from the reportable sig- 


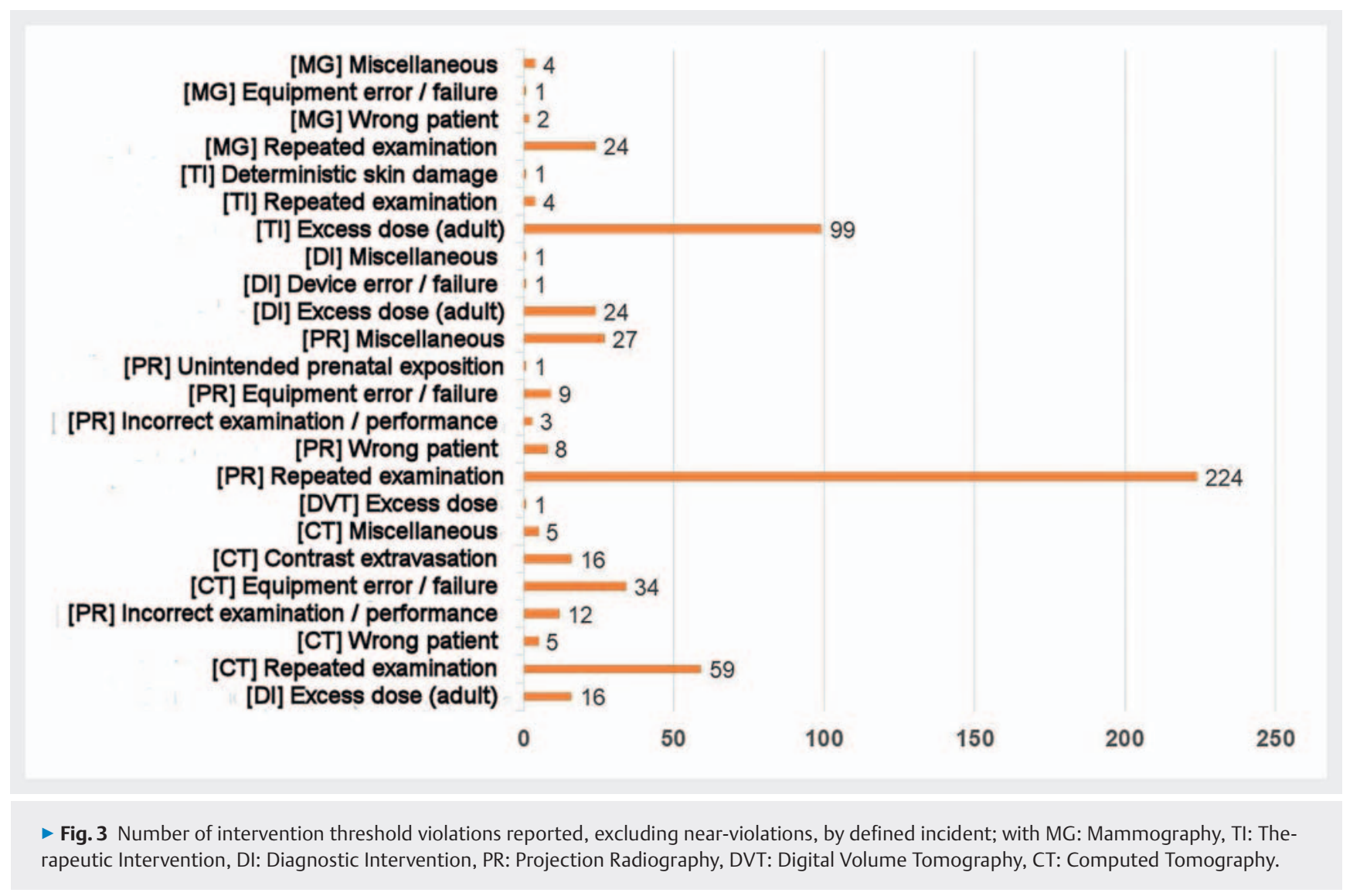

nificant incidents in this ordinance (Annex 14), which may have led to misunderstandings among participants between project specifications and legal requirements. In contrast, a significant decrease in reports in the area of therapeutic interventions could be due to successful reprocessing from previous reports.

In the course of the study, both the Radiation Protection Act and Radiation Protection Ordinance became effective using criteria other than those specified in the study. The study was deliberately continued with the largely lower-threshold criteria originally developed. The difference is significant with regard to the projection images, which are not considered in Annex 14 of the Radiation Protection Ordinance, and within the study represented a significant proportion of all threshold violations. Similarly, the study criteria included any type of repeat image and confusion of body parts and mistaken individuals, regardless of the dose applied. Intention of the lower thresholds was to record clinically "less serious" incidents as well, in order on the one hand, to reduce the likelihood of a recurrence of the incident through targeted reprocessing as well as to fundamentally promote a more transparent error policy. A reduction in the frequency of less serious incidents will also have a long-term effect on the frequency of serious incidents [25]. Against this background, the Radiation Protection Ordinance also calls for the implementation of a local quality management system to record and process less serious incidents.

Over the entire period, the project management is aware of the reporting of four significant incidents according to the criteria of the ordinance by all participating facilities to the respective competent authorities. Of these, three of the four incidents were subsequently determined by agency assessment to be not significant and non-reportable. Regarding the process between operators and authorities, it would be desirable from a clinical perspective to promote more transparency and exchange, as well as a detailed explanation of the background of why an incident would not be considered significant. The process between regulatory agencies and clinical facilities, analogous to clinical processes, has yet to be established.

In the course of the study and the discussion of reporting criteria, as well as in conversations with various groups of study participants, it became clear that the currently defined legal thresholds cause difficulties in some circumstances and create ambiguity and a lack of understanding. Thus, any mistaking of persons and body parts, in CT as well as in fluoroscopy, appears relevant only when the legal dose of the corresponding imaging category is exceeded. In light of the fact that conventional projection radiography is not included in the regulatory criteria, the question arises as to whether the inadvertent failure to switch off a system and the resulting high exposures do not constitute an incident. Diagnostic interventions involving DAP > 20000 cGycm² also raise the question of the extent to which a dose was intentional and whether there was a particular clinical challenge and justification, or the extent to which clinical protocols need revision. Likewise, the calculation of the moving average of different dose parameters is currently only reasonably possible via dose management systems (DMS). Not all commercially-available dose management systems contain this function. As a result of 


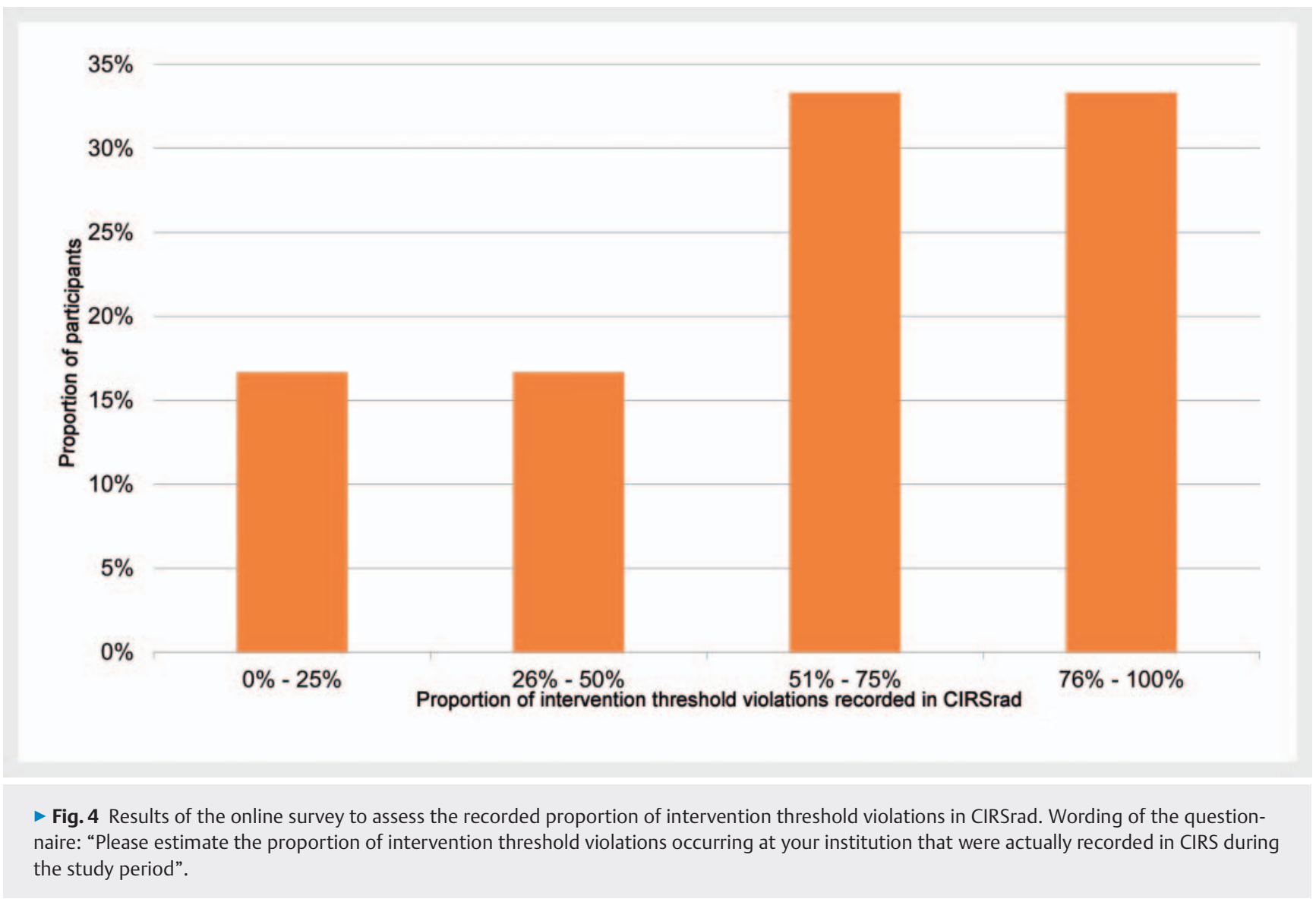

the online survey, some participants commented that it was "somewhat unclear to them when an exposure is unintentional" and others stated that there are "too many different conditions, some of which are unintelligibly or misleadingly interdependent of one another". It should also be noted that the reporting thresholds from Annex 14 and 15 of the Radiation Protection Ordinance are to be understood "in particular" as significant incidents. Accordingly, even if an incident is not explicitly listed in Annexes 14 and 15, it may well be considered an incident.

Dose management systems provide a useful basis for the detection of threshold violations or incidents and, if well integrated, allow filtering according to certain criteria, so that automated monitoring of dose values is possible. Increasingly, larger institutions are planning to implement a DMS, but especially for smaller practices it must be assumed that the detection of an incident must also be feasible with a simple DMS or other evaluation method. It is imperative to note that a DMS with dose threshold violations represents only a small fraction of all occurring incidents. For further information on the use of DMS and related problems, please refer to the German Federal Office for Radiation Protection research project "Evaluation of the use of dose management systems for the optimization of X-ray applications in various X-ray facilities" [26], the guide developed from it [27] as well as the publication by Loose et al. [28].

Dose management systems can facilitate incident handling and analysis. However, the personnel operating the equipment are crucial for the reliable recording and documentation of inci- dents. Reporting behavior and thus also the reduction of critical incidents can only function with attentive and motivated employees as well as through an established "error culture". Regular training, joint evaluations and discussions within the staff team, for example, during the annual briefings in accordance with paragraph 63 of the Radiation Protection Ordinance, ensure that the relevance of the topic is made clear. Especially in the phase of introducing reporting systems and incident disclosure, it is important to provide continuous training on the reporting process and to repeat the training regularly. Regular training and the thematization of incidents are of great importance with respect to complete and fully meaningful reports. A prerequisite for the functioning of a reporting system is an open approach to errors within the facilities as well as the constant awareness of the topic. In addition to the legally required reporting of significant incidents, the added value for the facility's own quality and risk management should also be mentioned. For example, regularly occurring deviations can be detected and corrected by analyzing the internally reported incidents, medical physics experts can use the documented incidents to optimize radiation protection, and the database of incidents can provide tips on activities and procedures.

\section{Conclusions}

It is possible to record incidents in a way that is not very time-consuming, meets the requirements of radiation protection law, and 
makes sense in terms of risk management. The software CIRSrad can record, analyze and follow up on incidents. During the oneyear observation period, 586 intervention threshold violations were recorded by 16 facilities. The number of reports can be increased by regular training of all those involved in recognizing and handling incidents, as well as openly dealing with errors in the operation.

A guideline for handling reportable incidents was prepared and published by the Federal Office for Radiation Protection [23]; this was based on experience gained, together with the research project "Operational handling of significant incidents in medical applications of radioactive substances in nuclear medicine". After completion of the project, the CIRSrad software was made available for free download for interested institutions [22].

\section{CLINICAL RELEVANCE OF THE STUDY}

- The Radiation Protection Act requires that incidents be addressed and significant incidents in the use of ionizing radiation be reported.

- As part of the study, incident recording software was developed and its use was tested in the clinical practice of various institutions.

- As part of the departmental research project, a workflow for recording, assessing, processing and reporting incidents was developed and its application tested in the daily clinical routine of various institutions. The guidance provided can assist in the development of facility-specific processes related to incident reporting.

\section{Funding}

Bundesamt für Strahlenschutz (3617S42333)

\section{Conflict of Interest}

The authors declare that they have no conflict of interest.

\section{Acknowledgments}

We would like to thank the German Federal Office for Radiation Protection for initiating the departmental research project 3617542333 and supporting the study "Operational handling of (significant) incidents in medical applications of ionizing radiation in $\mathrm{X}$-ray diagnostics and interventional radiology and practical testing of the reporting criteria".

\section{References}

[1] Brix G, Griebel J, Czarwinski R. Reporting and information system for significant events related to radiation exposures in medicine: Structure, responsibilities and reporting criteria. Z Med Phys 2019; 29: 66-76. doi:10.1016/j.zemedi.2018.11.003

[2] Clark BG, Brown RJ, Ploquin JL et al. The management of radiation treatment error through incident learning. Radiother Oncol 2010; 95: 344349. doi:10.1016/j.radonc.2010.03.022

[3] Kearney N, Denham G. Recommendations for Nuclear Medicine Technologists Drawn from an Analysis of Errors Reported in Australian Radiation
Incident Registers. | Nucl Med Technol 2016; 44: 243-247. doi:10.2967| jnmt.116.178517

[4] Williams MV. Radiotherapy near misses, incidents and errors: radiotherapy incident at Glasgow. Clin Oncol (R Coll Radiol) 2007; 19: 1-3. doi:10.1016/j.clon.2006.12.004

[5] Boadu M, Rehani MM. Unintended exposure in radiotherapy: identification of prominent causes. Radiother Oncol 2009; 93: 609-617. doi:10.1016/j.radonc.2009.08.044

[6] Bissonnette JP, Medlam G. Trend analysis of radiation therapy incidents over seven years. Radiother Oncol 2010; 96: 139-144. doi:10.1016/ j.radonc.2010.05.002

[7] Cunningham J, Coffey M, Knoos T et al. Radiation Oncology Safety Information System (ROSIS) - profiles of participants and the first 1074 incident reports. Radiother Oncol 2010; 97: 601-607. doi:10.1016/ j.radonc.2010.10.023

[8] Smith KS, Harris KM, Potters L et al. Physician attitudes and practices related to voluntary error and near-miss reporting. J Oncol Pract 2014; 10: 350-357. doi:10.1200/jop.2013.001353

[9] Montgomery L, Fava P, Freeman CR et al. Development and implementation of a radiation therapy incident learning system compatible with local workflow and a national taxonomy. J Appl Clin Med Phys 2018; 19 : 259-270. doi:10.1002/acm2.12218

[10] Martin C]. A survey of incidents in radiology and nuclear medicine in the West of Scotland. Br J Radiol 2005. doi:10.1259/bjr/20111483

[11] Martin C], Vassileva J, Vano E et al. Unintended and accidental medical radiation exposures in radiology: guidelines on investigation and prevention. J Radiol Prot 2017; 37: 883-906. doi:10.1088/1361-6498/ aa881e

[12] IAEA. SAFRAD - Safety in Radiological Procedures. Im Internet (Stand: 13.07.2020): https://www.iaea.org/resources/rpop/resources/ databases-and-learning-systems/safrad

[13] Kruskal JB, Siewert B, Anderson SW et al. Managing an acute adverse event in a radiology department. Radiographics 2008; 28: 1237-1250. doi:10.1148/rg.285085064

[14] Stecker MS, Balter S, Towbin RB et al. Guidelines for patient radiation dose management. J Vasc Interv Radiol 2009; 20: 263-273. doi:10.1016/j.jvir.2009.04.037

[15] Steele JR, Jones AK, Ninan EP. Quality initiatives: Establishing an interventional radiology patient radiation safety program. Radiographics 2012; 32: 277-287. doi:10.1148/rg.321115002

[16] Sendlhofer G, Leitgeb K, Kober B et al. The evolution of the Critical Incident Reporting System in an Austrian university hospital. Z Evid Fortbild Qual Gesundhwes 2016; 114: 48-57. doi:10.1016/j.zefq.2016.06.005

[17] Hoffmann B, Beyer M, Rohe J et al. "Every error counts": a web-based incident reporting and learning system for general practice. Qual Saf Health Care 2008; 17: 307-312. doi:10.1136/qshc.2006.018440

[18] Institut für Allgemeinmedizin, Frankfurt. Fehlerberichts- und Lernsystem für Hausarztpraxen; Jeder Fehler zählt! Im Internet (Stand: 13.07.2020): https://www.jeder-fehler-zaehlt.de/

[19] BÄK, KVB. Ärztliches Zentrum für Qualität in der Medizin. KrankenhausCIRS-Netz Deutschland 2.0. Im Internet (Stand: 13.07.2020): https:// www.kh-cirs.de/

[20] Hartmann J, Müller B, Singer ] et al. Betrieblicher Umgang mit (bedeutsamen) Vorkommnissen bei medizinischen Anwendungen ionisierender Strahlung in der Röntgendiagnostik und interventionellen Radiologie und praktische Erprobung der Meldekriterien - Vorhaben 3617542333 (04.01.2021). http://nbn-resolving.de/urn:nbn:de:02212021010624660, Stand: 28.02.2021

[21] Borowski M, Pirl L, Hartmann J et al. Betrieblicher Umgang mit (bedeutsamen) Vorkommnissen bei medizinischen Anwendungen radioaktiver Stoffe in der Nuklearmedizin und praktische Erprobung der Meldekriterien - Vorhaben 3617542332 (04.01.2021). http://nbn-resolving.de/ urn:nbn:de:0221-2021010624652, Stand: 28.02.2021 
[22] Pirl L, Borowski M, Hertlein T et al. CIRSrad - Critical Incident Reporting System for Radiology and Nuclear Medicine. https://www.apt.drg.de/ de-DE/5979/cirsrad/, Stand: 28.02.2021

[23] Borowski M, Hartmann J, Müller B et al. Leitfaden zum Umgang mit Vorkommnissen in Röntgendiagnostik und Nuklearmedizin - Vorhaben 3617542332 und 3617542333 (04.01.2021). http://nbn-resolving.de/ urn:nbn:de:0221-2021010624674, Stand: 28.02.2021

[24] Oechler LS. Analyse von Fehlaufnahmen bei Röntgenuntersuchungen: Technische Hochschule Mittelhessen, Campus Gießen. 2019

[25] Heinrich HW. Industrial accident prevention: a scientific approach. New York: McGraw-Hill; 1931

[26] Hartmann J, Singer J, Fiebich M et al. Bewertung des Einsatzes von Dosismanagementsystemen zur Optimierung von Röntgenanwendungen und Einhaltung von Referenzwerten - Vorhaben 3616S42432 (04.01.2021). http://nbn-resolving.de/urn:nbn:de:02212021010424630, Stand: 21.03.2021

[27] Hartmann J, Singer J, Fiebich M et al. Leitfaden zum Einsatz von Dosismanagementsystemen zur Optimierung von Röntgenanwendungen und Einhaltung von Referenzwerten - Vorhaben 3616542432 (04.01.2021). http://nbn-resolving.de/urn:nbn:de:02212021010424644, Stand: 21.03.2021

[28] Loose RW, Vano E, Mildenberger P et al. Radiation dose management systems-requirements and recommendations for users from the ESR EuroSafe Imaging initiative. Eur Radiol 2021; 31: 2106-2114. doi:10.1007/s00330-020-07290-x 